\title{
A stereoscopic method for dihedral angle measurement
}

\author{
L. FELBERBAUM, A. ROSSOLL, A. MORTENSEN * \\ Laboratory for Mechanical Metallurgy, Institute of Materials, Swiss Federal Institute of \\ Technology in Lausanne (EPFL), CH-1015 Lausanne, Switzerland \\ E-mail: andreas.mortensen@epfl.ch
}

\begin{abstract}
A new method is presented for the measurement of equilibrium dihedral angles in intergranular inclusions, and illustrated with pure copper containing $1 \mathrm{wt} \%$ lead. The method is based on the selective dissolution of inclusions visible along a polished metallographic section. Scanning electron microscopy stereo image pairs are then taken and processed so as to enable a three-dimensional digital reconstruction of the inclusion/matrix interface along each inclusion. Spherical caps describing the $\mathrm{Cu} / \mathrm{Pb}$ interface over non-facetted orientations are then fitted to the measured digital inclusion envelope reconstructions. Knowing the center and radius of these spheres, the true dihedral angle of each specific inclusion can then be deduced with good precision.

It is found that the true dihedral angle in the $\mathrm{Cu} / \mathrm{Pb}$ alloy is not a unique function of temperature, reflecting the (known) anisotropy of high-angle grain boundary energy in copper. (c) 2005 Springer Science + Business Media, Inc.
\end{abstract}

\section{Introduction}

Liquid inclusions embedded in a solid that has a finite solubility in the liquid provide a path for rapid diffusion of solid atoms situated along the liquid/solid interface. As a consequence, the shape of such inclusions is often dictated by capillary equilibrium. When the inclusions lie along grain-boundaries of the surrounding solid (as they often do in practice), their shape is influenced by the grain boundary: at capillary equilibrium, the inclusions form a cusp along their line of intersection with the grain boundary.

In the absence of torque components that can arise with very low angle grain boundaries [1] capillary equilibrium along this line of intersection dictates that:

$$
\cos (\phi / 2)=\gamma_{11} / 2 \gamma_{12}
$$

where angle $\phi$ is the dihedral angle, Fig. $1, \gamma_{11}$ is the interfacial energy between identical phases, and $\gamma_{12}$ is the interfacial energy between different phases. In the present situation, $\gamma_{11}$ is the grain boundary energy $\gamma_{\mathrm{gb}}$, and $\gamma_{12}$ is the solid-liquid interface energy $\gamma_{\mathrm{SL}}$. Given its importance in the microstructures of materials, and given the information it conveys on interfacial and grain boundary energy values, there has long been high interest in measuring $\phi$ with good precision, e.g., Ref. [2].

A difficulty encountered in practice when measuring $\phi$ is that many materials are not transparent to light. Therefore, unlike contact angles for which the sessile drop technique provides an elegant and geomet- rically unambiguous three-dimensional (3D) measurement technique, dihedral angles must often be observed in two dimensions, along polished metallographic planes that cut randomly through the sample and its inclusions. In practice, apparent two-dimensional (2D) dihedral angles are measured either directly at the tip of a surface groove, at the apex of intergranular inclusions, or alternatively for regular lens-shaped inclusions such as that depicted in Fig. 1 by using a simple equation linking the apex angle with the width and thickness of a 2D lens [3].

Since metallographic planes cut the inclusions randomly, the problem arises of converting such 2D angles into their real 3D value $\phi$ defined above. To this end, a variety of techniques and analyses have been proposed, all of which (i) necessitate the characterization of a large (typically 100) number of inclusions, and (ii) rely on a priori assumptions concerning the distribution of the dihedral angle within the alloy (generally, it is assumed that a single angle exists, in which case the median of the 2D measurement distribution tends toward this 3D angle) [4-10]. Such methods are thus cumbersome and tributary to methods and assumptions used in data analysis.

Another approach is to conduct precise threedimensional measurements of individual dihedral angles, as is done in the sessile drop method for wetting angles. Stereoscopic and statistical mathematical data analysis are then avoided, easing interpretation and increasing the reliability of the data. Two methods are generally used to this end. 


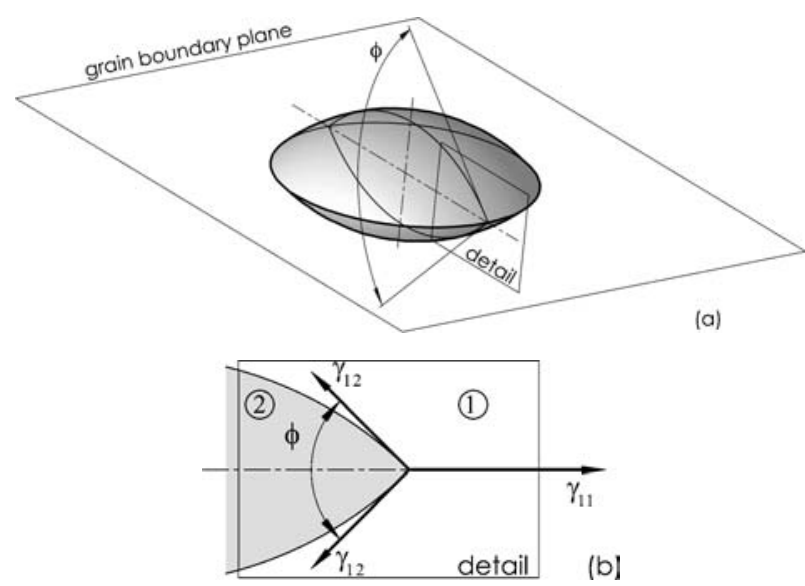

Figure 1 Schematic view of an equilibrated lenticular inclusion situated on a planar grain boundary: (a) 3D view, and (b) detail: the cut is perpendicular to both the grain boundary and the triple line.

One is to create and examine the "external" angle at individual grain boundary grooves, formed along the lines of intersection of a grain boundary with a free surface. If the free surface of a sample is wetted by the liquid metal, the liquid-filled grain boundary groove shape is governed by the dihedral angle $\phi$ of Equation 1. Three-dimensional effects are resolved if the orientation of the grain boundary along the free surface is known (a 2D cut perpendicular to the grain boundary can then be obtained). Mullins' treatment of the shape of grain boundary grooves [11] can then be used to extrapolate the liquid/solid interface to the bottom of the groove, so as to deduce the value of $\phi$ [12].

A second technique for direct measurement of $\phi$ is transmission electron microscopy (TEM) on samples containing inclusions that are sufficiently small to be embedded within an electron-transparent metallographic sample. With sufficient contrast between matrix and inclusion, the inclusion can be clearly distinguished. With adequate tilting of the sample and taking other precautions, the dihedral angle of a single inclusion can then be measured. Gabrisch et al. made in-situ TEM measurements of dihedral angles using this method, reporting the influence of (i) faceting, (ii) free surfaces, and (iii) projection errors on the measurement of the dihedral angle on a single inclusion [13]. The inclusions are typically nanoscopic (100 nm or less), often causing their shape to be influenced by size effects, such as "magic size" phenomena observed with inclusions a few nanometres wide $[14,15]$. This approach is also limited to temperatures below that at which inclusions start migrating along the grain boundaries towards the sample free surface; with $\mathrm{Al} / \mathrm{Pb}$ this temperature is around $500^{\circ} \mathrm{C}[13,16]$.

We present here a different three-dimensional method for the direct measurement of dihedral angles, based on scanning electron microscopy (SEM) of inclusions that are far larger than those currently used in TEM. The method begins with the selective dissolution of inclusions intersected by a polished metallographic section of samples previously treated at elevated temperature and rapidly quenched so as to preserve the liquid inclusion shape. The three-dimensional inclusion/surrounding metal interface is then measured stereoscopically and extrapolated to the line of contact with a planar grain boundary, yielding the true threedimensional "macroscopic" dihedral angle $\phi$ of the inclusion in question. In a sense, this method resembles the sessile drop technique, in that it provides precise, three-dimensional measurements of a "macroscopic" angle defined by extrapolation of the geometry of simple and fully equilibrated liquid drops. We illustrate the method with samples of relatively pure copper containing lead inclusions, a well-known system that has been previously characterized by several authors [17-21].

\section{Experimental procedures}

\subsection{Materials}

$\mathrm{Cu}-1 \mathrm{wt} \% \mathrm{~Pb}$ alloys were prepared from $5 \mathrm{~N}$ pure metals by induction melting in a high purity ( $\geq 99.999 \mathrm{vol} \%$ ) argon atmosphere. Lead at this concentration forms well-defined isolated inclusions in essentially lead-free solid copper. The inclusions, on the order of $1 \mu \mathrm{m}$ in size, are either intergranular and lenticular in shape, or located in the grain interiors; they are then spherical.

Cylindrical specimens, $6 \mathrm{~mm}$ long and $6 \mathrm{~mm}$ in diameter, were used. All heat treatments were conducted in the presence of a titanium sponge oxygen scavenger in a dynamic primary vacuum for all samples except for the $930^{\circ} \mathrm{C}$ anneal, which was conducted in Formier gas $\left(95 \% \mathrm{~N}_{2}, 5 \% \mathrm{H}_{2}\right)$. A two-step treatment was applied:

(i) $1 \mathrm{~h}$ at $900^{\circ} \mathrm{C}$ to induce microstructural coarsening, causing the inclusions to grow to a size of roughly $10 \mu \mathrm{m}$;

(ii) a hold at fixed temperature above the melting point of lead, sufficiently long to reach shape equilibration of the lead inclusions. The duration of this heat treatment was varied as a function of the temperature (it was $60 \mathrm{~h}$ at $400^{\circ} \mathrm{C}$ and $1 \mathrm{~h}$ at $900^{\circ} \mathrm{C}$ ). Following this hold, the samples were quenched in water. It can be shown by diffusion rate analysis [22] that these time/temperature combinations are sufficient for shape equilibration of the $10 \mu \mathrm{m}$ inclusions during the isothermal hold, while the inclusions do not have time to change shape during the quench (the quench cools the samples in water in a few seconds, as shown by simple estimation with a heat-transfer coefficient typical for non-agitated water, $\left.\mathrm{h} \approx 10^{3} \mathrm{~W} \mathrm{~m}^{-2} \mathrm{~K}^{-1}[23]\right)$

\subsection{Metallography}

The inclusions were dissolved using a procedure designed by superposing the Pourbaix diagrams for lead and copper: this reveals that, at a $\mathrm{pH}$ of 4 and at zero electrical potential, copper is immune while lead is corroded. Agitated and desaerated pure acetic acid is thus used to selectively dissolve exposed lead inclusions along a polished metallographic cut through the samples, leaving the copper essentially intact. The etchant is desaerated by bubbling $\mathrm{N}_{2}$ in order to prevent oxidation of the metal surface.

Stereo image pairs are then obtained from such samples in scanning electron microscopy using the $\mathrm{MeX}^{\circledR}$ 
stereophotogrammetry computer program [24]. This software combines images captured after dual tilting of the stage to produce three-dimensional reconstructions of the sample surfaces along the surface of dissolved inclusions.

An important parameter with samples such as these is the surface roughness that exists along the metal surface where inclusions were dissolved. The software bases its reconstruction of the dissolved inclusion surface using the two captured SEM images on identifying and matching selected points along this surface. This step of the process is easily conducted on fractographs (for which the software was originally designed); however, it becomes near-impossible if the copper surface is perfectly smooth after lead dissolution. A proper compromise must therefore be reached between (i) leaving, after etching, a surface that is sufficiently smooth so that the true overall geometry of the inclusion surface is preserved, and (ii) producing a small degree of surface roughening so as to aid the software in identifying selected points that can be "matched" along the inclusion surface across the two SEM micrographs. In this respect, partial solidification along the interface of the (small) amount of copper initially dissolved into the liquid inclusion is somewhat helpful as it can produce small features along the interface. Practically, an adequate inclusion surface was obtained by fine-tuning the time of the etch, and also by selecting the "best" inclusions in terms of relative surface roughness-in addition to other criteria such as their relative location with respect to the plane of polish and the degree of planarity of the grain boundary along which they are located.

\subsection{Data processing}

From these images, the $3 \mathrm{D}$ dataset is numerically processed so as to enable a three-dimensional digital reconstruction of the visible copper/lead interface along each inclusion, Fig. 2a. Assuming that the solid-liquid interfacial energy is isotropic (see below), spherical caps describing the solid-liquid interface over non-facetted orientations can then be fitted to the measured digital inclusion envelope reconstructions, Fig. 2b. Provided the inclusion is located along a planar grain boundary, knowing the center and radius of these two spheres, the true dihedral angle $\phi$ along the circular line of intersection of the two inclusions is then easily deduced.

The dihedral angle $\phi$ was also measured on the same samples using the "classical" statistical method

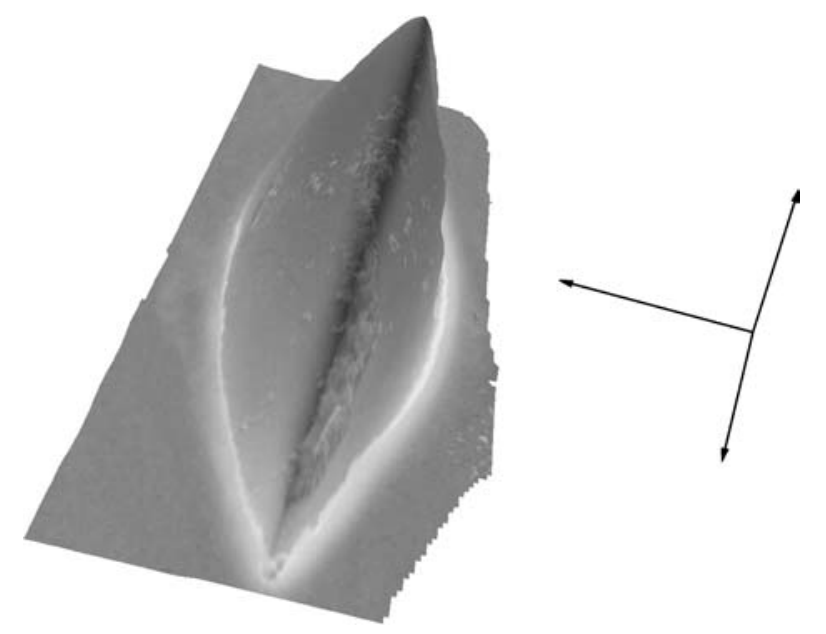

(a)

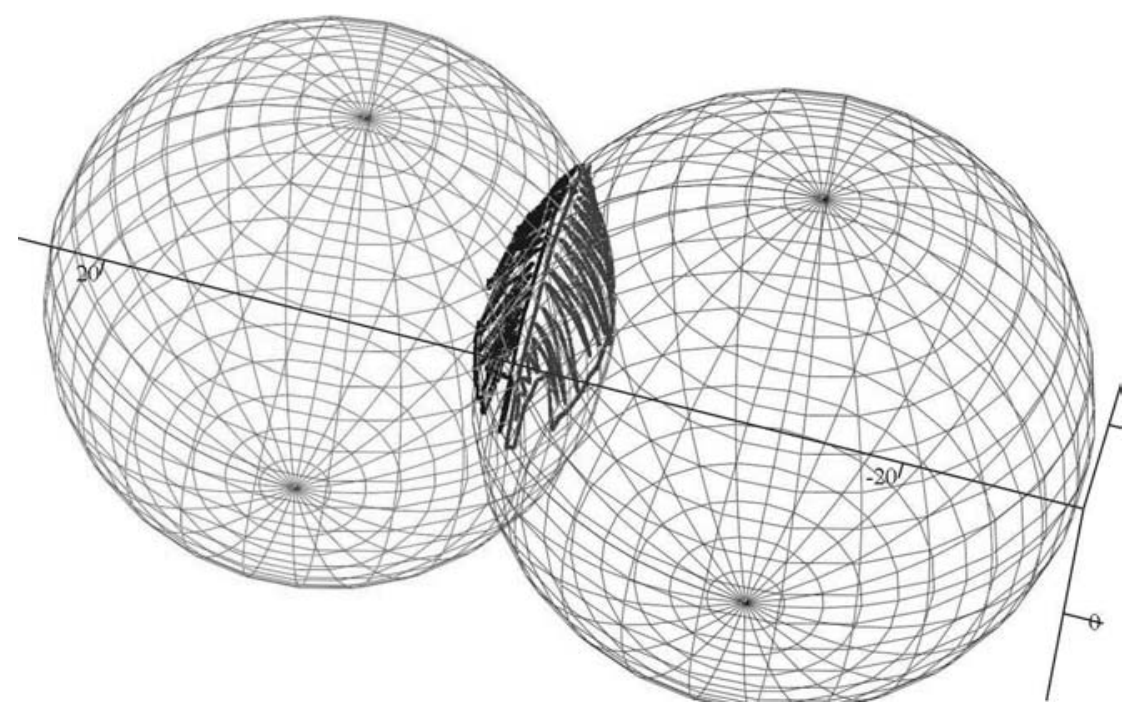

(b)

Figure 2 (a) 3D digital reconstruction of the solid-liquid interface of an intergranular inclusion, and (b) data points from each cap with the two fitting spheres. The $\mathrm{Cu}-1 \mathrm{~Pb}$ sample was heat treated at $930^{\circ} \mathrm{C} ; \phi=78^{\circ}$. 


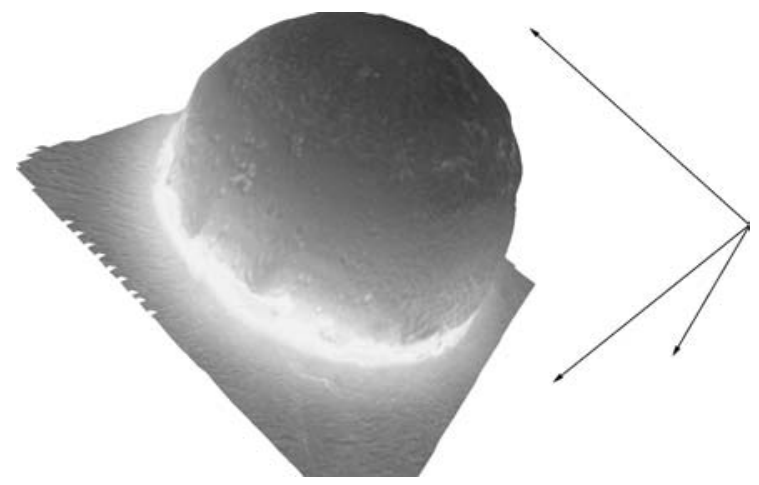

(a)

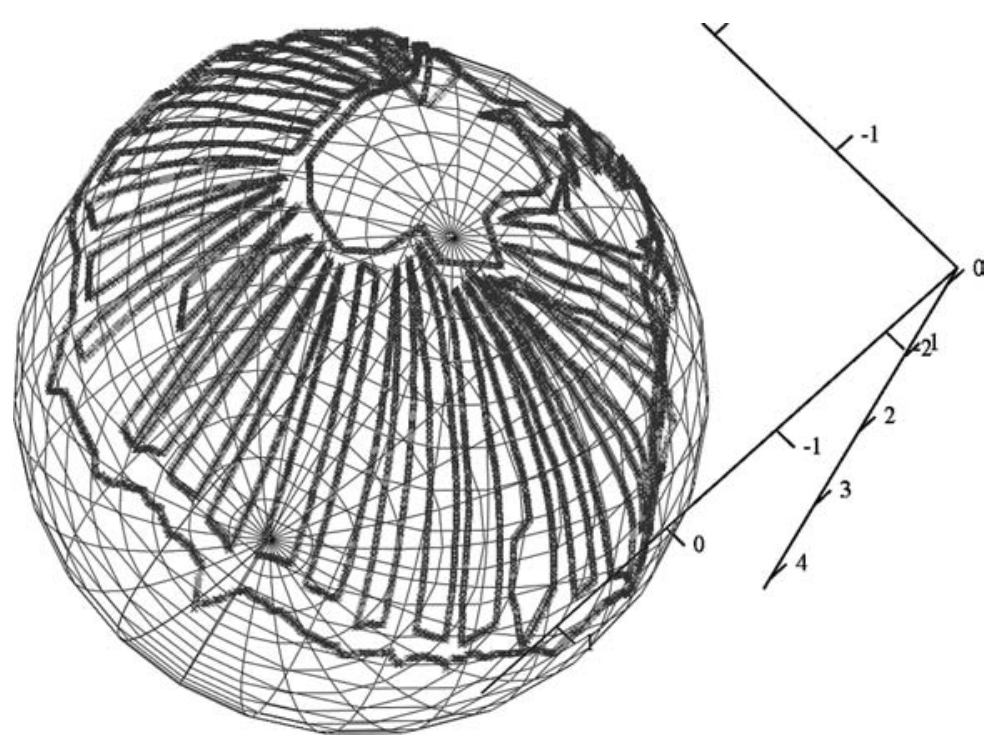

(b)

Figure 3 (a) 3D digital reconstruction of the solid-liquid interface of an intragranular inclusion, and (b) data points with the fitting sphere. The $\mathrm{Cu}-1 \mathrm{~Pb}$ sample was heat treated at $930^{\circ} \mathrm{C}$

described above: the median of more than 100 apparent "internal" angles visible in the SEM on a 2D longitudinal cut was determined for samples treated at 400,820 , 900 and $930^{\circ} \mathrm{C}$.

\section{Results}

Observation of intragranular inclusions confirms that the solid-liquid interfacial energy is isotropic in this system: intragranular inclusions are spherical, save for isolated facets that form within limited solid angles at low temperature. Faceted inclusions were observed in samples heat treated at $400^{\circ} \mathrm{C}$, the lowest temperature used. At $930^{\circ} \mathrm{C}$, a mean deviation to sphericity of $3.2 \%$ was measured out of $16^{\prime} 000$ data points from a single spherical inclusion envelope, Fig. 3.

Using the present dissolution method, the dihedral angle $\phi$ of several inclusions was measured in specimens equilibrated during the second step of heattreatment at temperatures ranging from 400 to $970^{\circ} \mathrm{C}$; individual results are plotted in Fig. 4. This plot also gives results for the measurement of $\phi$ using many inclusions according to the "classical" statistical method, as well as data (also gathered using the "classical" statistical method) for this system from two references in the literature, namely the work of Ikeuye and Smith who performed about 250 measurements with an optical microscope along a longitudinal cut of a $\mathrm{Cu}-1 \mathrm{~Pb}$ alloy annealed in a reducing atmosphere [17], and

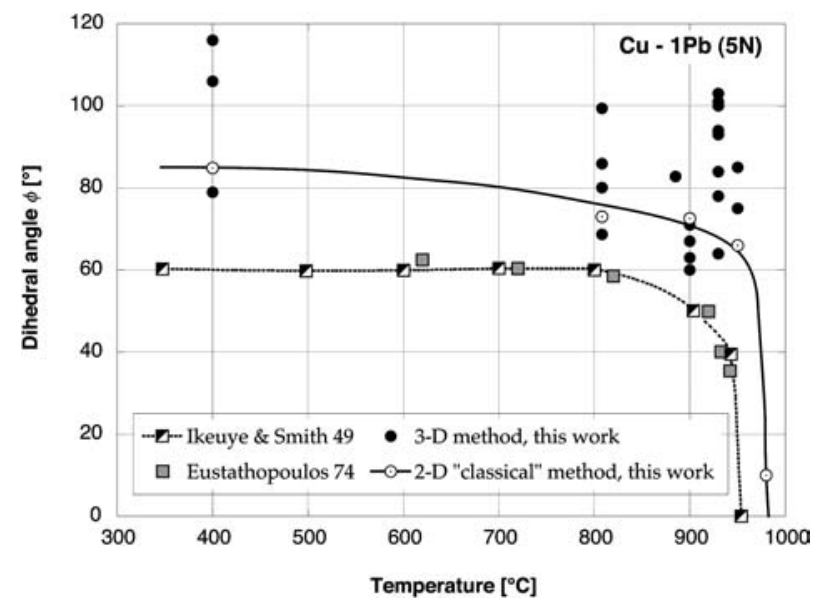

Figure 4 Solid/liquid dihedral angle, $\phi(T)$, as a function of heat treatment temperature for the $\mathrm{Cu}-\mathrm{Pb}$ system. Our measurements, circular symbols, are compared with literature data [17, 19]. Open dotted circles are measurements on the alloy of this work using the classical statistical method. Solid circles are measured dihedral angles of individual single inclusions using the method presented here.

Eustathopoulos et al. who made 100 measurements with similar experimental conditions on a $\mathrm{Cu}-10 \mathrm{~Pb}$ alloy [19].

It is seen that the dihedral angle measured on different inclusions with the method presented here varies significantly from inclusion to inclusion at each temperature. Adjacent intergranular inclusions located on 

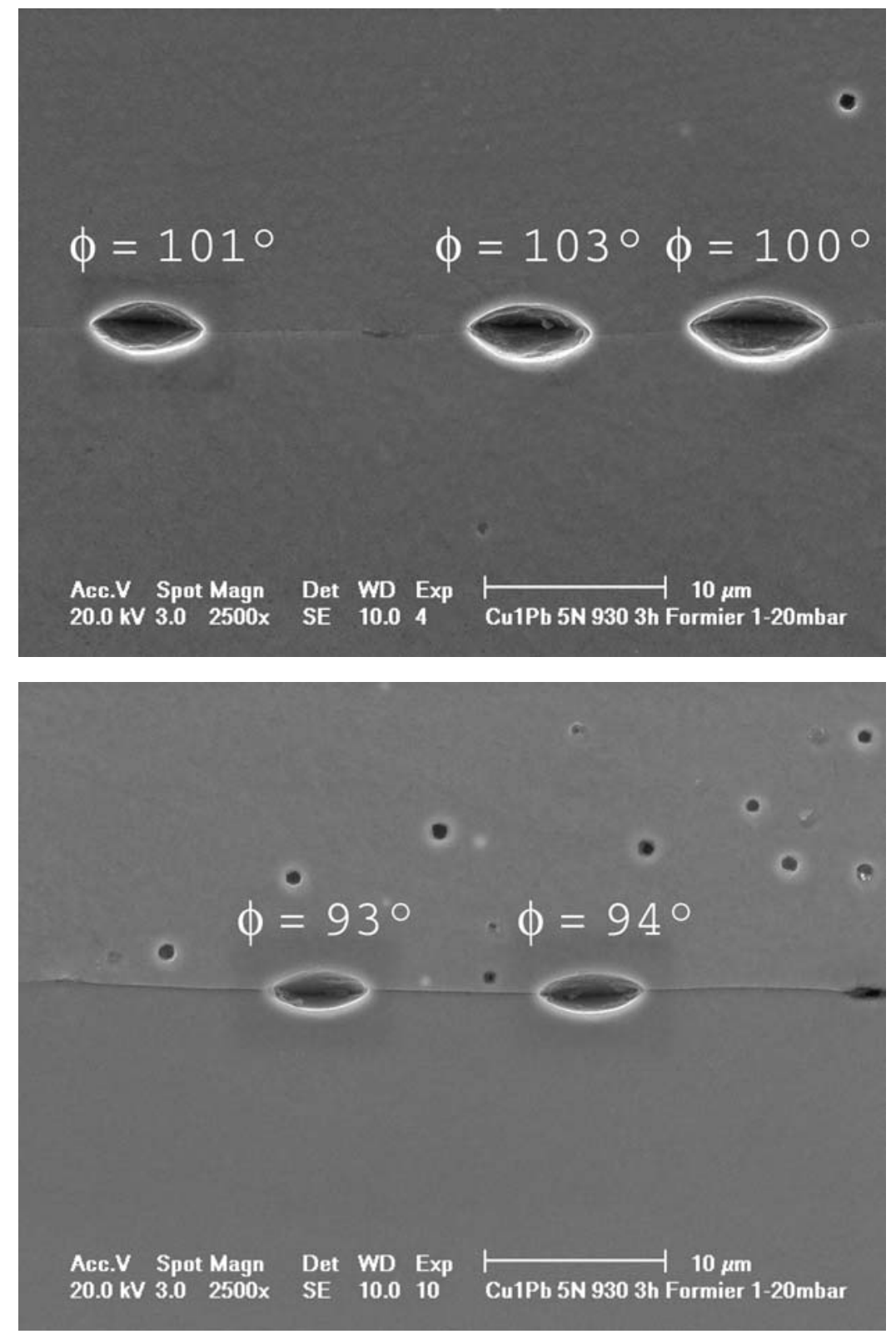

Figure 5 SEM micrographs displaying two sets of neighbouring dissolved inclusions situated on a planar grain boundary. The dihedral angle measured by $3 \mathrm{D}$ reconstruction of each inclusion is indicated on the figure next to the inclusion.

a single planar grain boundary are, on the other hand, characterized by the same dihedral angle, Fig. 5 .

\section{Discussion}

\subsection{Solid/liquid interfacial energy}

Apart from facets that appear around a few crystallographic directions at relatively low temperature $\left(400^{\circ} \mathrm{C}\right)$, the solid $\mathrm{Cu}$-liquid $\mathrm{Pb}$ interfacial energy is found to be isotropic in the temperature range explored. The small measured deviation of intragranular inclusions from a perfectly spherical shape can easily be attributed to roughness along the surface of the dissolved inclusions, and/or to error in the measurement and digital reconstruction of the interface.

This agrees with the literature. It is known that $\mathrm{Al} / \mathrm{Pb}$ and $\mathrm{Cu} / \mathrm{Pb}$ systems are quite similar [25-28]. In the former, more extensively characterized system, when the inclusions are liquid partial faceting occurs along $\{111\}$ planes below a certain temperature, which increases with particle diameter in the range of 30 to $300 \mathrm{~nm}$, approaching $500^{\circ} \mathrm{C}$ for larger particles $[16,25]$. Above $500^{\circ} \mathrm{C}$, the interfacial energy is also documented to become isotropic [25]. These observations for $\mathrm{Al} / \mathrm{Pb}$ are fully consistent with present observations on larger lead inclusions in copper.

\subsection{The method}

The method presented here yields measurements of true (3D) dihedral angles for individual inclusions that are significantly larger $(10 \mu \mathrm{m})$ than those typically used in TEM $(=300 \mathrm{~nm})$. Size effects, such as a sizedependence in particle shape or roughening temperature, which are characteristic of submicron inclusions and become exacerbated at very small sizes, are thus absent here. Measuring dihedral angles with larger inclusions such as those used here, also presents a few additional advantages:

(i) as shown by a simple calculation given elsewhere [22], with a diameter around $10 \mu \mathrm{m}$ the liquid 
inclusion is small enough for capillary shape equilibration in a few hours during heat-treatment, yet it is also too large to change its shape significantly during a simple quench (e.g., of a millimeter-sized sample in water). Measurement of inclusion geometry and hence of dihedral angles is thus possible over a wider range of temperatures than in TEM;

(ii) given the size of the inclusions, the triple line energy, which can intervene in nanometric inclusions, is also safely neglected;

(iii) at elevated temperature, the influence of misfit elastic energy, found to be significant with very small liquid inclusions [14-16] is more likely to be negligible. The reason is that the ease of dislocational relaxation of particle elastic misfit increases with particle size $[29,30]$, such that the influence of elastic energy on particle shape is likely to be less important than with nanometric particles, particularly at elevated temperature.

The dihedral angle value obtained with the present method results from an extrapolation of overall smooth inclusion interfaces, essentially as is done in the sessile drop technique for contact angles. As such, the measurement yields a "macroscopic" angle $\phi$ that reflects the overall energetic optimization of inclusion shape as implicit in the derivation of a capillary equilibrium equation such as Equation 1. This implies for example that the effect of grain boundary facets, which are important at the atomic length scale and affect the local dihedral angle where they meet the inclusion apex, are neither important nor captured.

The reproducibility of the method is apparent by analysis of several inclusions located along the same grain boundary, Fig. 5: as seen, $\phi$ is constant to within roughly one or two degrees. Compared with "statistical" 2D methods, the present method is thus quite precise. We note in passing that $\phi$ values in Fig. 5 are near $90^{\circ}$, which is deemed the more difficult value for measurement of $\phi$ using 2D statistical methods. When $\phi$ is very low, on the other hand, the present method is less convenient because the stereoscopic reconstruction becomes challenging if the inclusion envelopes feature steep and narrow channel-like walls. In one instance, the 3D reconstruction of an inclusion was also performed twice, thus using different datapoints for the fit of the spheres. Measured $\phi$ values from these two pairs of spheres determined were $114^{\circ}$ and $116^{\circ}$. In conclusion, for well-oriented inclusions the method has a precision of roughly two degrees in $\phi$.

It is clear that if the grain boundary plane is not perpendicular to the image, the reconstruction of one of the spherical caps will be of lower quality due to shadowing effects. Moreover, if the inclusion is cut closer to its periphery, making its visible surface smaller on the 2D cut, the accuracy of the measurement of $\phi$ will also be lower. Optimum results are thus obtained by selecting inclusions that are (i) favourably oriented relatively to the polished section, and (ii) are cut trough the middle of their periphery, since meeting these two conditions enables the highest number of datapoints to be collected.

\subsection{Dihedral angles in $\mathrm{Cu}-\mathrm{Pb}$}

Variations in the value of $\phi$ that we find at each specific temperature using the present method do not reflect experimental error since adjacent intergranular inclusions display the same angle. The reason is rather that the grain boundary energy is far more anisotropic than the solid-liquid interfacial energy, in accordance with Clarke and Gees' expectations [31]. If we consider the measurements made on the specimen annealed at $930^{\circ} \mathrm{C}$ (which shows the largest degree of variation in measured $\phi$ ), the angles vary between 64 and $103^{\circ}$. From Equation 1, this implies a ratio of $4 / 3$ between the corresponding extreme values of grain boundary energy $\gamma_{\mathrm{gb}}$. Such a range of variation of high-angle grain boundary energy is consistent with the literature, as concerns both experimental data and atomistic computer simulations $[32,33]$.

Such variations in $\phi$ as a result of high-angle grain boundary energy anisotropy have been noted before. Protsenko et al. observed a distribution in groove depths in polycrystalline nickel wetted by silver at $1040^{\circ} \mathrm{C}$ and attributed this to the anisotropy of the grain boundary energy [34]. Disregarding any "special" low energy grain boundary, a $\sim 7 / 5$ ratio between the higher and lower grain boundary energies in nickel can be estimated from their work.

The disagreement between dihedral angle values we measure and the data available in the literature for $\mathrm{Cu}$ $\mathrm{Pb}[17,19]$ does not seem to arise from the method used: our "2D classical" method measurements yield values that are in good agreement with the average of our "3D" measurements, in accordance with De Hoffs' mathematical treatment [10]. Also, no difference is found between the two annealing atmospheres used here (the $930^{\circ} \mathrm{C}$ data conform with those for other temperatures). The disagreement therefore must arise from the presence of grain boundary contaminants in our alloy compared to the higher-purity samples of Refs. [17, 19]. Since enrichment factors are reported to be more than one order of magnitude higher at grain boundaries than at solid-liquid interfaces [35], a segregated element will reduce $\gamma_{\mathrm{gb}}$ more significantly than $\gamma_{\mathrm{SL}}$, and in turn increase the dihedral angle $\phi$, Equation 1. Waterhouse and Grubb also provide data documenting an increase in $\phi$ due to grain boundary contamination in $\mathrm{Cu}-\mathrm{Pb}$ annealed at $650^{\circ} \mathrm{C}$ [36]: they report a value of $93^{\circ}$, which is close to values found here and well above the value of $60^{\circ}$ documented in $[17,19]$. According to Waterhouse, in reply to Stickels' comments, this is due to the presence of $0.08 \% \mathrm{P}$ added as a desoxidizing agent, the phosphorous segregation thus reducing the $\gamma_{\mathrm{gb}} / 2 \gamma_{\mathrm{SL}}$ ratio [37].

In one instance, though, it may be that disagreement between our results and literature data is due to the method used. This is at $400^{\circ} \mathrm{C}$, where inclusions are facetted, making the classical method fairly difficult to apply: "classically" measured values of $\phi$ in the literature may therefore be underestimated. Even in the case of uncontaminated $\mathrm{Cu}-\mathrm{Pb}$ alloys, lead may segregate at grain boundaries at such an intermediate temperature, similarly as it spreads and forms a monolayer on a free surface of copper ahead of a liquid droplet of lead 
[38-40]. This would also produce a decrease of the grain boundary energy, which may increase the dihedral angle, even in samples of very high purity. Higherpurity samples than those used here would be needed to resolve the question.

\section{Conclusions}

A new method is presented for the determination of the dihedral angle of intergranular liquid inclusions; it is based on quantitative scanning electron microscopic analysis of metallographic surfaces along which quenched inclusions have been dissolved. The angle is derived from a mathematical fitting of the solid/liquid interface geometry around individual inclusions, and therefore reflects the dihedral angle dictated by global energy minimization of the inclusion shape under capillary forces, as expressed by Equation 1. As such, this method parallels the sessile drop method for contact angle measurement, where the drop shape is used to deduce "macroscopic" contact angles.

Compared with classical methods of dihedral angle measurement, no statistical treatment of the data is needed. The method also overcomes some shortcomings of other techniques, such as the direct measurement of dihedral angles at grain boundary grooves or in transmission electron microscopy.

We show that the $\mathrm{Cu} / \mathrm{Pb}$ solid-liquid interfacial energy is isotropic above $400^{\circ} \mathrm{C}$, save for a slight tendency for faceting at $400^{\circ} \mathrm{C}$. Even in the presence of facets, the method presented here leads to reliable measurements of the true dihedral angle $\phi$. For a specific temperature, we show that $\phi$ is not unique; this reflects the fact that high-angle grain boundary energies vary in the material. Coupled with EBSD methods for characterization of grain orientation in the scanning electron microscope, the present method for dihedral angle measurement can therefore be extended to provide a new indirect SEMbased method for the measurement of grain boundary energies.

\section{Acknowledgements}

This work was supported by internal funds of the Laboratory for Mechanical Metallurgy at EPFL.We gratefully acknowledge enlightening discussions on the subject of this work with Professor Nicolas Eustathopoulos, of the Institut National Polytechnique de Grenoble in France and Dr. Emmanuel Vincent, of Swissmetal, Reconvilier, Switzerland. We thank Prof. Pierre Stadelmann, of EPFL, Lausanne, Switzerland for all the help in learning the $\mathrm{MeX}^{\circledR}$ software, and the Swissmetal company for donating the materials used in this work. One of the authors, LF, also thanks Profs. E. Rabkin and D. Chatain for their helpful comments at iib 2004 in Belfast.

\section{References}

1. C. H. P. LUPIS, in "Chemical Thermodynamics of Materials" (North-Holland, Elsevier, New York, Amsterdam, 1983) p. 375.

2. N. EUSt A thopoulos, Intern. Met. Rev. 28 (1983) 189.

3. T. MORI, H. MIURA, T. TOKITA, J. HAJI and M. KA TO, Philosoph. Mag. Lett. 58 (1988) 11.
4. C. S. S MITH, Trans. Amer. Inst. Mining Metall. Eng. 175 (1948) 15.

5. D. HARKER and E. R. PARKER, Trans. Amer. Soc. Met. 34 (1945) 156.

6. O. K. RIEGGER and L. H. VAN VLACK, Trans. Amer. Inst. Mining Metall. Engng. 218 (1960) 933.

7. C. A. STICKELS and E. E. HUCKE, Trans. Metall. Soc. AIME 230 (1964) 795.

8. S. R. JUREWICZ and A. J. G. JUREWICZ, J. Geophys. Res.-Solid Earth Plan. 91 (1986) 9277.

9. M. A. FORTES and A. C. FERRO, Metall. Trans. A-Phys. Metall. Mater. Sci. 19 (1988) 1147.

10. R. T. DE HOFF, Metallography 19 (1986) 209.

11. W. W. MUllins, Trans. Metall. Soc. AIME 218 (1960) 354.

12. E. RAB KIN and L. KLINGER, Adv. Engng. Mater. 3 (2001) 277

13. H. GABRISCH, U. DAHMEN and E. JOHNSON, Microsc. Res. Techn. 42 (1998) 241.

14. U. DAHMEN, S. Q. XIAO, S. PACIORNIK, E. JOHNSON and A. JOHANSEN, Phys. Rev. Lett. 78 (1997) 471.

15. E. JOHNSON, A. JOHANSEN, U. DAHMEN, S. CHEN and T. FUJII, Mater. Sci. Engng. A 304-306 (2001) 187.

16. H. GABRISCH, L. KJELDGAARD, E. JOHNSON and U. D A HMEN, Acta Materialia 49 (2001) 4259.

17. K. K. IKEUYE and C. S. S MITH, Met. Trans. 185 (1949) 762.

18. W. M. R OBERT S O N, Trans. Metall. Soc. AIME 233(1965) 1232.

19. N. Eustathopoulos, L. COUduRier, J. C. JOUd and P. J. DESRE, Journal de chimie physique 71 (1974) 1465.

20. L. RATKE and H. J. VOGEL, Acta Materialia 39 (1991) 915.

21. I. APYKHTINA, B. BOKSTEIN, A. KHUSNUTDinOVA, A. PETELINE and S. RAKOV, Defect and Diffusion Forum 194-199 (2001) 1331.

22. L. FELBERBAUM, "Microstructure and Embrittlement of Leaded Copper Alloys," Ph.D. Thesis \#3217, EPFL, Lausanne, Switzerland, 2005.

23. D. R. POIRIER and G. H. GEIGER, "Transport Phenomena in Materials Processing." (TMS, Warrendale, PA, 1994) p. 267.

24. MeX software, Alicona Imaging GmbH, Graz (2004), http://www.alicona.com.

25. K. I. MOORE, D. L. ZHANG and B. CANTOR, Acta Metallurgica et Materialia 38 (1990) 1327.

26. W. T. KIM and B. CANTOR, ibid. 40 (1992) 3339.

27. R. GOSWAMI and K. CHATTOPADHYAY, ibid. 43 (1995) 2837.

28. R. GOSWAMI, K. CHATTOPADHYAY and P. L. RYDER, Acta Materialia 46 (1998) 4257.

29. M. F. ASHBY and L. JOHNSON, Philosoph. Mag. 20 (1969) 1009.

30. J. W. MATtheW S, in "Dislocations in Solids," edited by F. R. N. Nabarro (North-Holland Publ., New York, 1979) p. 461.

31. D. R. CLARKE and M. L. GEE, in "Materials Interfaces Atomic-Level Structure and Properties," edited by D. Wolf and S. Yip (Chapman \& Hall, London, 1992) p. 255.

32. G. HASSON, J.-Y. BOOS, I. HERBEUVAL, M. BISCONDI and C. GOUX, Surf. Sci. 31 (1972) 115.

33. D. WOLF, J. Mater. Res. 5 (1990) 1708.

34. P. PROTSENKO, Y. KUCHERINENKO, F. ROBAUT, V. TR AS KINE and N. EUS T A THOPOUlos, Def. Diff. Forum 216/217 (2003) 225.

35. D. ChAtAin, C. VAhlas and N. Eustathopoulos, Acta Metall. 32 (1984) 227.

36. R. B. WATERHOUSE and D. GRUB B, J. Inst. Met. 91 (1963) 216.

37. C. A. STICKELS, J. Inst. Met. 91 (1963) 422

38. G. RAO, D. B. ZHANG and P. WYNBLATT, Acta Metallurgica et Materialia 41 (1993) 3331.

39. G. PREVOT, C. COHEN, J. M. GUIGNER and D. SCHMAUS, Phys. Rev. B 61 (2000) 10393.

40. J. MOON, J. LOWEKAMP, P. WYNBLATT, G. STEPHEN and R. M. SUTER, Surf. Sci. 488 (2001) 73.

Received 29 July 2004

and accepted 31 January 2005 